\title{
Restrictive cardiomyopathy in a female patient
}

\author{
(D)Rreze Koshi* \\ General Hospital Gjakova, \\ Gjakova, Republic of Kosovo
}

KEYWORDS: restrictive cardiomyopathy, female, cardiac resynchronization therapy. CITATION: Cardiol Croat. 2019;14(9-10):248. | https://doi.org/10.15836/ccar2019.248

*ADDRESS FOR CORRESPONDENCE: Rreze Koshi, General Hospital Gjakova, 122 Ismail Qemali, Gjakova 50000, Republic of Kosovo. / Phone: 00377(383)44236610 / E-mail: rreze.koshi@gmail.com ORCID: Rreze Koshi, https://orcid.org/0000-0002-7653-2332

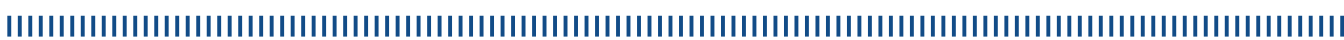

Introduction: Secondary (or functional) mitral regurgitation (MR) frequently accompanies heart failure syndromes and is associated with poor prognosis. ${ }^{1}$ Initial surgical approaches failed to impact on outcome in contrast with optimized medical therapy, cardiac resynchronization therapy (CRT), longterm ventricular assist devices, and cardiac transplantation

Case report: The aim of this case is to follow up the median age of the female patient with restrictive cardiomyopathy which is idiopathic and with incipient type 2 diabetes and hypothyroidism. The patient was diagnosed 9 years ago, and she was in regular therapy with beta-blockers, ACE-inhibitors, antithrombotic and diuretics. The echocardiography was with grade $2+\mathrm{MR}$, grade $1+$ aortic regurgitation grade 1+ tricuspid regurgitation, and with EF $40 \%$. Last year she was admitted again which is acute pericarditis and arrythmia which was not corrected with antiarrhythmics. The analyses of antiphospholipid syndrome were negative, but she was with hypothyroidism and cholelithiasis which is also treated. The patient was also in therapy of arrythmia drugs, also continuing with diuretics and antidiabetics, but advised for resynchronization ICD or CRT. She was admitted for resynchronization and she is with CRT and the same medical therapy without antiarrhythmics and continuing treatment of diabetes and hypothyroidism.

Conclusion: The patient with idiopathic restrictive cardiomyopathy should follow up and considering a good medication therapy and should convinced for further step of general condition to be treated and carriage for life.
RECEIVED:

August 4, 2019

ACCEPTED:

September 16, 2019

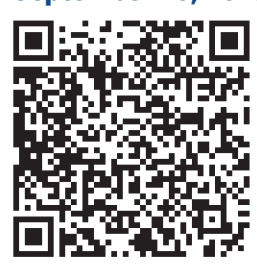

$\square$ Cardiologia Croatica 2019;14(9-10):248. 